\title{
Poisson's Ratio of Some Structural Alloys for Large Strains
}

\section{By Ambrose H. Stang, Martin Greenspan, and Sanford B. Newman}

\begin{abstract}
Values of Poisson's ratio, as well as ordinary stress-strain properties, for tensile strains as high as 18 percent, were determined on sheets of aluminum alloys 24ST and 24SRT, chrome-molybdenum steel plate, and structural and fully killed low-carbon steel plate.
\end{abstract}

\section{Introduction}

\section{General}

In 1943 the Bureau decided to undertake an investigation on the elastic, and especially the plastic, properties of various materials under simple tension, with particular reference to the variation of Poisson's ratio with axial strain for large strains. Shortly thereafter the Army Air Forces Matériel Command expressed interest in the project, and the work was carried on as a cooperative enterprise. The pressure of other activities made it necessary to restrict the investigation mainly to the materials in which the Matériel Command was immediately interested; these were aluminum alloys $24 \mathrm{ST}$ and $24 \mathrm{SRT}$ sheet in several thicknesses and chrome-molybdenum steel plate $1 / 4$ in. thick. Some additional results, obtained on structural steel angles and plates and on a fully killed low-carbon steel in connection with other investigations, are included in this paper.

Very few values of Poisson's ratio in the plastic range for structural materials have been published. Lessells and MacGregor [1] ${ }^{1}$ report results for one specimen of nickel-chrome-molybdenum steel and Plank [2] for one specimen of mild steel.

\footnotetext{
1 Figures in brackets indicate the literature references at the end of this
} paper.

\section{Contents}

I. Introduction

1. General . . . . . . . . . . . . . 211

2. Nomenclature _. . . . . . . . . . . . . . . 212

II. Materials and specimens _. .

III. Methods of test_. _...

1. Loading _.......... 213

2. Strain measurements _............. 213

(a) Elastic strains _............. 213

(b) Small plastic strains _......... 213

(c) Large plastic strains _.......... 214

3. Computations _.............. 215

IV. Results and discussion _......... 215

1. Variation of properties with direction in a sheet of aluminum alloy $24 \mathrm{ST} \ldots \ldots \ldots 215$

2. Aluminum alloy $24 \mathrm{ST} \ldots \ldots \ldots 216$

3. Aluminum alloy 24 SRT _... _. _. . . . 218

4. Chrome-molybdenum steel_..._. _..... 218

5. Low-carbon steel, fully killed at $-44^{\circ} \mathrm{C}_{-} 218$

6. Low-carbon steel, fully killed at room temperature ................... 219

7. Structural low-carbon steel_________. 220

V. Appendix-Variation of Poisson's ratio with axial strain in an ideal case............... 221

VI. References_... 221 


\section{Nomenclature}

The term "stress" is here used to denote the stress based on original cross-sectional area. The term "strain" refers to the classical "extension," namely, the change in length of the gage line, reckoned from the original length, divided by the original length. The "axial strain," $\epsilon_{a}$, is the strain parallel to the axis of the specimen and the load, and is here always positive as all the specimens were tested in tension. The term "lateral contraction" denotes the transverse strain, $\epsilon_{t}$, which is always negative in these tests, along the width of the specimen in the case of sheet specimens, and the average value for all directions at right angles to the axis of the specimen in the case of round specimens.

The literature fails to disclose any accepted convention for the definition of Poisson's ratio for finite strains. The choice of a definition would, of course, be influenced by the definition adopted for strain itself. For the present purpose it was considered simplest to take Poisson's ratio, $\nu$, as

$$
\nu=-\epsilon_{t} / \epsilon_{a} .
$$

The data are presented in such a manner that they may be readily expressed in terms of any

\section{Materials and Specimens}

The materials tested were aluminum alloy $24 \mathrm{ST}$ sheet in six thicknesses, aluminum alloy 24SRT sheet in two thicknesses, chrome-molybdenum steel plate $1 / 4$ in. thick, fully killed lowcarbon steel plates $11 / 2$ in. thick, and structuralsteel plates $3 / 8$ in. thick and angles $1 / 2$ in. thick. The number of specimens of each is given in table 1.

TABLE 1.-Number of specimens tested

[Direction refers to angle between direction of rolling and direction of tensile load]

\begin{tabular}{c|c|c|c|c|c|c|c}
\hline \hline Direction & $0^{\circ}$ & $15^{\circ}$ & $30^{\circ}$ & $45^{\circ}$ & $60^{\circ}$ & $75^{\circ}$ & $90^{\circ}$ \\
\hline Nominal thickness & \multicolumn{4}{|c}{ Number of specimens }
\end{tabular}

ALUMINUM ALLOY 24ST SHEETS

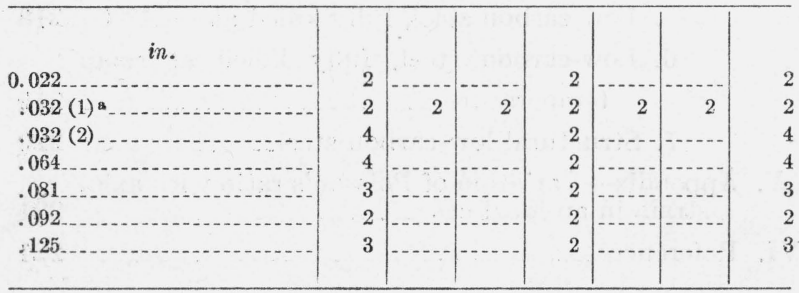

alternate expressions for strain and Poisson's ratio that one may adopt.

The term "direction", in obvious context, denotes the angle between the direction of rolling of the material and the axis of the specimen (or the load), in the plane of the sheet or plate. These rolled materials are assumed to be orthotropic, with two planes of symmetry perpendicular to the plate, one parallel to, and one perpendicular to the axis of rolling. Thus specimens whose axes make equal but opposite angles with the direction of rolling are equivalent, or have the same direction, and the possible directions lie between $0^{\circ}$ and $90^{\circ}$ only.

The standard deviation, $\sigma$, of a set of $n$ quantities $X_{i}(i=1,2, \ldots n)$ is the root-mean-square deviation of the $X_{i}$ from the average $\bar{X}$. That is [3],

$$
\sigma=\left[\frac{\sum_{i=1}^{n}\left(X_{i}-\bar{X}\right)}{n}\right]^{1 / 2}
$$

If the distribution of the $x_{i}$ is normal, about two-thirds of the $X_{i}$ lies between $\bar{X}-\sigma$ and $\bar{X}+\sigma$. In an actual case less than two-thirds of the $X i$ lies between these limits.
TABLE 1.-Number of specimens tested-Continued

\begin{tabular}{c|c|c|c|c|c|c|c}
\hline \hline Direction & $0^{\circ}$ & $15^{\circ}$ & $30^{\circ}$ & $45^{\circ}$ & $60^{\circ}$ & $75^{\circ}$ & $90^{\circ}$ \\
\hline Nominal thickness & \multicolumn{5}{|c}{ Number of specimens } \\
\hline
\end{tabular}

ALUMINUM ALLOY 24SRT SHEETS

\begin{tabular}{r|r|r|r|r|r|r|r}
\hline in. & 2 & & & & & & 2 \\
0.025 & 2 & & 2 & \\
\hline
\end{tabular}

CHROME-MOLYBDENUM STEEL PLATE

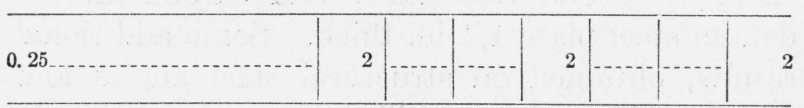

CARBON-STEEL, FULLY KILLED PLATES

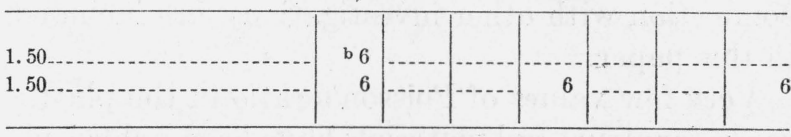

STRUCTURAL LOW-CARBON STEEL PLATES AND ANGLES

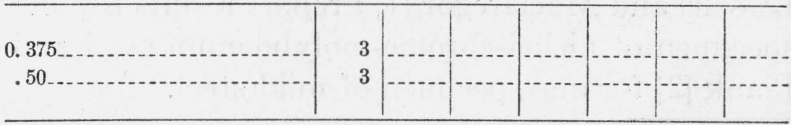

specimens (1) and (2) were not from the same sheet.

b These 6 specimens were tested at a temperature of $-44^{\circ} \mathrm{C}$. All other specimens were tested at room temperature. 
Most of the sheet material was tested in the three directions 0,45 , and 90 degrees, but one sheet of aluminum alloy $24 \mathrm{ST}, 0.032$ in. thick, was tested in seven directions 15 degrees apart, as shown in table 1 .

The chrome-molybdenum steel was SAE X4130, condition $A$ (annealed) and was supposed to comply with Army-Navy specification AN QQS-685.

The carbon steel, fully killed, was from a lot especially rolled for another investigation and had the following composition: Carbon 0.22 percent, manganese 0.56 percent, phosphorus 0.016 percent, sulfur 0.028 percent.
The low carbon structural steel, complied with ASTM Specification A7-42 for Steel for Bridges and Buildings. The chemical composition was carbon 0.25 percent, manganese 0.39 percent, phosphorus 0.011 , and sulfur 0.036 percent.

The specimens from the fully killed carbon steel plates, 1.5 in. thick, were of circular cross section and 12 in. long over-all. The diameter of the 9 in. long reduced portion was $1 \frac{1}{8}$ in., and the ends were $13 / 8$ in. in diameter.

The other specimens were all of the as-rolled thickness of the material. They were 16 in. long over-all, 2 in. wide at the ends, and had a width of $1.75 \mathrm{in}$. in the $5 \mathrm{in}$. long reduced portion:

\section{Methods of Test}

\section{Loading}

Except as noted below, all of the sheet and plate specimens were loaded in either of two BaldwinSouthwark hydraulic testing machines (capacities 20 kips and 60 kips) equipped with TateEmery weighing systems. In the case of the 0.032 -in. sheet of $24 \mathrm{ST}$ from which specimens were taken in seven directions, the loading in the elastic range was accomplished by means of a single dead weight of $953.0 \mathrm{lb}$., corresponding to a stress of about $17 \mathrm{kips} / \mathrm{in}^{2}$.

The sheet and plate specimens were in all cases held in 2 -in.-wide Templin grips, capacity 20 kips.

The round steel specimens were held in threaded adapters and loaded in an Amsler horizontal hydraulic testing machine, capacity 100 kips.

Except in the case of six of the fully killed carbon steel specimens, all tests were performed at room temperature. The steel specimens were tested in connection with another investigation and the tests were performed at a temperature of about $-44^{\circ} \mathrm{C}$. Preliminary tests had indicated that this fully killed steel was as ductile at $-44^{\circ} \mathrm{C}$ as many ordinary ship steels are at room temperature, and the tensile tests confirmed this conclusion. The low temperature was maintained by solid $\mathrm{CO}_{2}$ in an insulated box surrounding the specimen, and was measured by means of two copper-constantan thermocouples attached one near each end of the reduced portion of the specimen.

Most of the specimens were strained, in the plastic range, at a rate of about 0.8 percent per minute. Of the aluminum alloy $24 \mathrm{ST}$, four specimens, two at 0 and two at 90 degrees, from each of two sheets $(0.032 \mathrm{in}$. and $0.064 \mathrm{in}$.) were strained at a rate of about 3.2 percent per minute. This 4 to 1 variation in speed had no appreciable effect on the values of Poisson's ratio obtained, and therefore, speed over the range of low speeds used in these tests was not considered a significant variable.

\section{Strain Measurements}

\section{(a) Elastic Strains}

Method a-1.- In most cases these were determined by means of Tuckerman optical strain gages, 1-in. gage length. There were two gages parallel to the axis of the specimen, opposite each other at midwidth; these had 0.5 -in. lozenges. Two gages having 0.2 -in. lozenges were similarly disposed at right angles to the axis of the specimen. The load was applied slowly and then held constant while the strain gages were read.

Method a-2.- In the case of the 0.081-in. 24ST sheet and the fully killed carbon steel, the elastic strains were determined by means of SR-4 electric strain gages of various types $(A-1, A-3, A-5)$ used in conjunction with SR-4 portable strain indicators. The disposition of the gages was the same as of the Tuckerman gages of method. a-1.

\section{(b) Small Plastic Strains}

Method $b-1$.-Wherever method a-1 had been used for the elastic strains, the same Tuckerman gages were used in the intermediate range. Each 
gage was reset to a point near the beginning of the range and initial readings were taken on all four gages. The testing machine was then operated at a constant rate of head separation, and simultaneous readings of load and of transverse strain on one side of the specimen were taken at predetermined readings of the axial gage on the other side of the specimen. When the range of the gages was nearly exhausted, the straining was stopped and the load reduced slightly and held constant as the four gages were read again. The bending in the specimen was determined from the readings of the mutually opposite gages. The readings that had been taken on only one side of the specimen were corrected to the average value. This correction was usually small, rarely exceeding 1 percent. The axial strain amounted to about 3 percent as the straining was stopped for this series of measurements.

Method b-2.-The electric strain gages of method a-2 were employed until the gages failed, usually at an axial strain of about 1 percent for tests at $-44^{\circ} \mathrm{C}$ and of about 2.5 percent for tests at room temperature.

\section{(c) Large plastic strains}

Method $c-1$.-Preliminary tests showed that the larger plastic strains were not uniform along the length or width of the specimen, so that values of Poisson's ratio computed from the strains at midwidth of the specimen were irregular. However, satisfactory results could be obtained by using average strains over a "gage square" about as wide as the specimen. Such a square was scribed on one side of the specimen at midlength. It consisted of three axial and three transverse gage lines, spaced $3 / 4 \mathrm{in}$. apart. The ends of the axial gage lines were marked by the two outside transverse gage lines, and the lengths of the axial lines were measured before and after straining by means of a traveling microscope having a least count (estimated place) of $0.001 \mathrm{~mm}$. The width of the specimen at each of the three transverse gage lines was measured before and after straining by means of a special outside micrometer constructed from two dial gages having a least count (estimated place) of $0.00001 \mathrm{in}$. After each increment of strain the specimen was removed from the testing machine and the gage lines were measured. The average axial and transverse permanent sets corresponding to the load attained when straining was stopped were computed from these data, the set of the middle gage line in either direction being given double weight in obtaining the average. The total strain in either direction was taken as the average permanent set plus the recovery strain for that direction. The recovery strains were computed from the slopes of the loadrecovery strain lines obtained by means of Tuckerman strain gages during unloading of the specimen just prior to removing it from the testing machine for measurement of set.

This procedure is based on the commonly observed facts (see e. g. [4]) that for ductile metals an interrupted tensile test gives a family of stressstrain curves of which the envelope is the stressstrain curve for a continuous test, and that the stress-recovery strain curve is practically linear. Small effects, such as elastic hysteresis and the elastic after-effect, are neglected.

This method gave very satisfactory results even though the axial strains were measured on one side of the specimen only. The indications were that the bending of these thin specimens at high strains were inconsiderable. However, the method is time-consuming and tedious. Furthermore, the intermittent loading of the aluminum alloys produced a pronounced tendency toward the formation of Lüders' lines [5]. A specimen which had been stretched 2 or 3 percent and then unloaded usually exhibited very distinct Lüders' lines upon reloading. These appeared one or only a few at a time, accompanied by small but abrupt variations in the load and frequently by clicks. A typical set of Lüders' lines is shown in the photograph, figure 1. The angle between the trace of the slip plane on the surface and the axis of the specimen was the same, about 60 degrees, for all specimens, the direction and the thickness of the specimen seemingly having no effect. These Lüders' lines produced no irregularity in the values of Poisson's ratio provided the gage square was either completely full or completely devoid of the lines. The data obtained when the gage square was partially covered with lines had to be discarded. Occasionally, after the Lüders' lines had completely covered the surfaces of the specimen, they disappeared upon further straining, and in some cases a second set would eventually appear.

Method C-2.-After the transfer strain gages described in [6] had been developed they were used for the remainder of the tests. The axial strains were measured by means of three gages on one side of the specimen and the transverse strains by means 


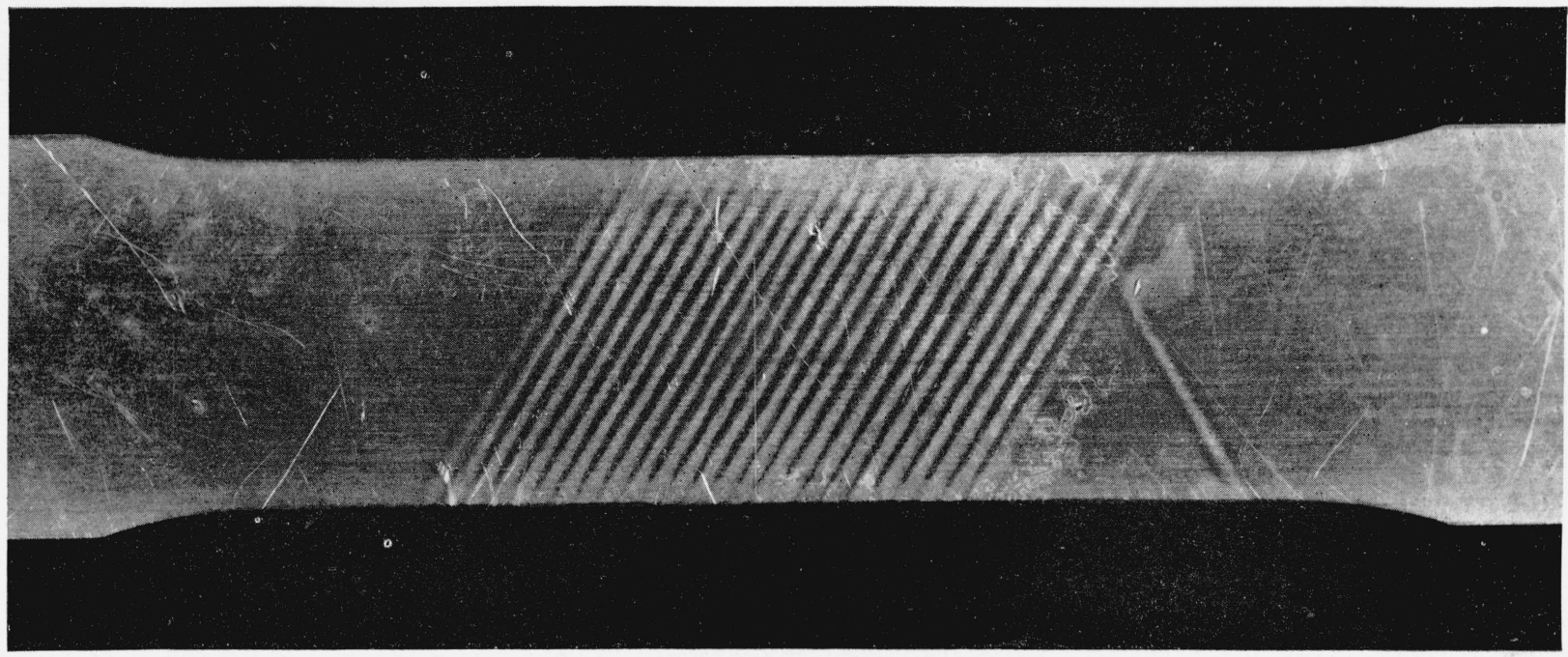

FIGURE 1.-Lüders' lines on aluminum alloy $24 S T$.
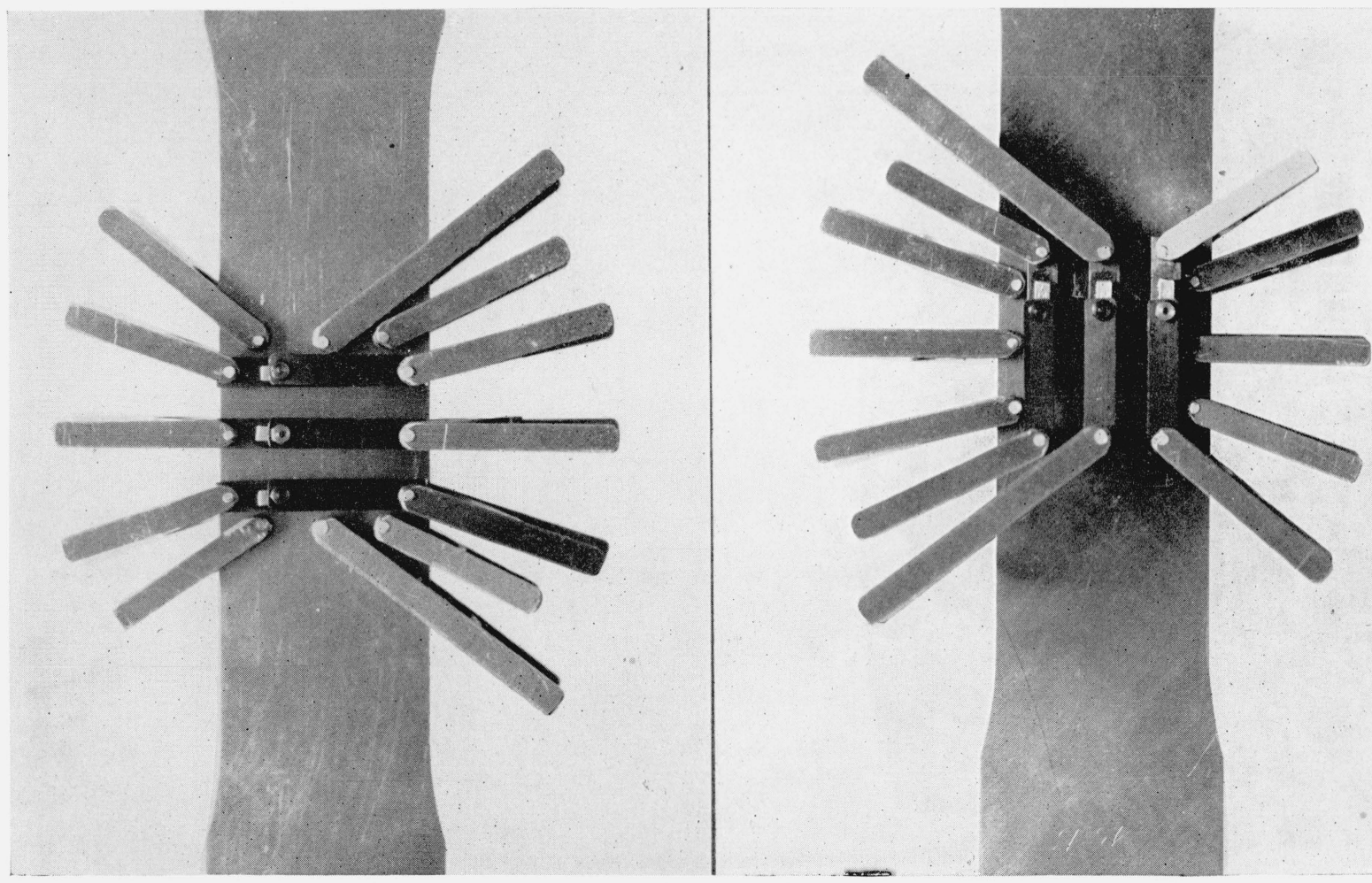

FIGURE 2.-Transfer strain gages on a tensile-test specimen of aluminum alloy $24 S T$ sheet. 
of three gages on the other side of the specimen as shown in figure 2. This method allowed a continuous test and gave good results, but was timeconsuming and tedious.

\section{Computations}

Young's modulus of elasticity, $E_{A}$ and the "transverse modulus of elasticity, " $E_{T}$ (slope of the linear part of the axial stress-transverse strain curve) were obtained from residual plots [7]. Poisson's ratio in the elastic range was taken as $\nu_{0}=-E_{\boldsymbol{A}} / E_{T}$.

The axial stress was plotted against axial strain on semilogarithmic paper (strain on log scale) and faired. The lateral contraction was plotted against axial strain on logarithmic paper and Poisson's ratio was computed at various points along the faired curve.

\section{Results and Discussion}

\section{Variation of Properties With Direc- tion in a Sheet of Aluminum Alloy 24ST}

The elastic constants, in terms of Young's modulus, $E_{A}$, transverse modulus, $E_{T}$, and Poisson's ratio are shown in figure 3 . The circles represent the results of the measurements. The curves are of the type that would be expected for a homogeneous orthotropic material [8] having two planes of symmetry perpendicular to the sheet, one parallel to, and one perpendicular to the direction of rolling. The curves for Young's modulus and the transverse modulus were fitted to the data by least squares; the curve for Poisson's ratio was computed from the other two. It is evident from figure 3 that the sheet has a definite elastic anisotropy, although it is so small,
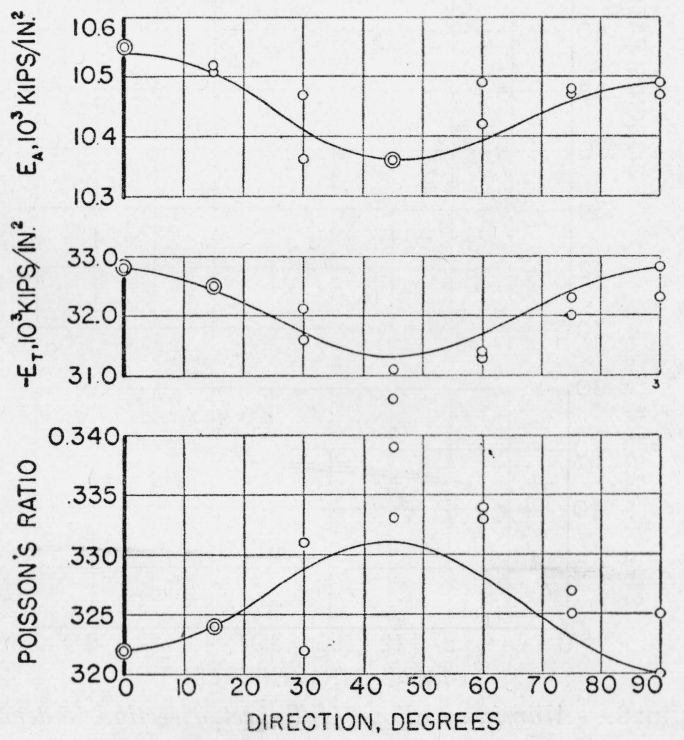

FIgURE 3.-Variation of elastic constants with direction in aluminum alloy $24 S T$ sheet, 0.032 in. thick.

The circles represent the measured values. especially in consideration of the scatter between two specimens in the same direction, that it would scarcely be noticed if the loads were applied in a testing machine rather than by dead weights.

The results in the plastic range are shown in figure 4, in which each curve is an average for two specimens. The scatter to be expected in a group of nominally identical specimens of $24 \mathrm{ST}$ is discussed in following sections. It is seen that for a given direction Poisson's ratio increases, reaches a maximum, and then decreases as the axial strain increases. This behavior is characteristic of practically all of the specimens tested and is qualitatively the same as for an ideal case of no plastic dilatation in an isotropic material, as will be shown in section $V$. The axial-stress axial-strain curves are shown in figure 4 for directions $0,15,45$, and 90 degrees. The 60- and
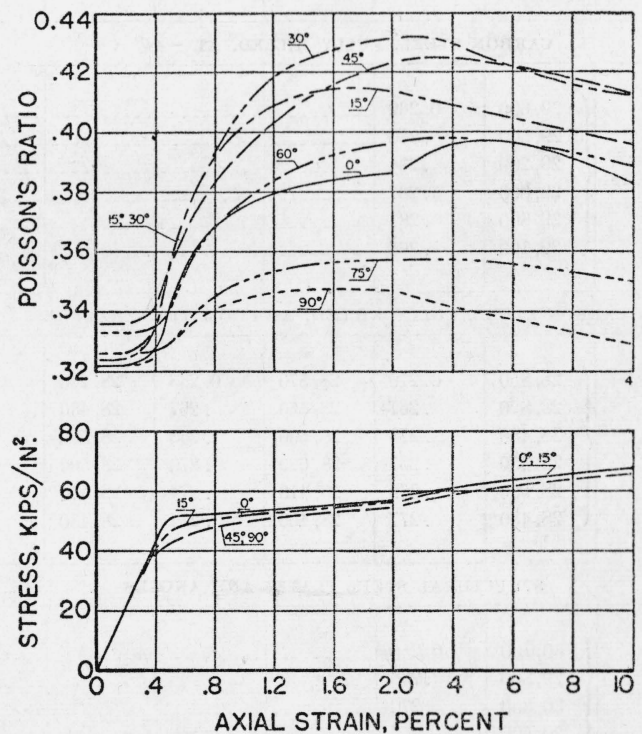

Figure 4.-Aluminum alloy $24 S T$ sheet, 0.032 in. thick. Each curve represents the average for two specimens. Note change of axial-strain scale at 2 percent. 
75-degree curves are identical and lie just above the 45- and 90-degree curve. The 30-degree curve lies between the 15-degree curve and the 60 and 75-degree curve, closer to the latter. These curves show that the tensile stress-strain curves vary with direction most rapidly near the knees

TABLE 2.-Young's modulus of elasticity and Poisson's ratio for specimen tested in the elastic range

\begin{tabular}{|c|c|c|c|c|c|c|}
\hline \multirow{3}{*}{$\begin{array}{l}\text { Nominal } \\
\text { thickness }\end{array}$} & \multirow{3}{*}{$\begin{array}{l}\text { Young's } \\
\text { modulus }\end{array}$} & \multicolumn{5}{|c|}{ Direction, degrees } \\
\hline & & \multirow{2}{*}{$\frac{0}{\begin{array}{c}\text { Poisson's } \\
\text { ratio }\end{array}}$} & \multicolumn{2}{|c|}{45} & \multicolumn{2}{|c|}{90} \\
\hline & & & $\begin{array}{l}\text { Young's } \\
\text { modulus }\end{array}$ & $\begin{array}{c}\text { Poisson's } \\
\text { ratio }\end{array}$ & $\begin{array}{l}\text { Young's } \\
\text { modulus }\end{array}$ & $\begin{array}{l}\text { Poisson's } \\
\text { ratio }\end{array}$ \\
\hline \multicolumn{7}{|c|}{ ALUMINUM ALLOY 24ST } \\
\hline In. & Kips/in. ${ }^{2}$ & & Kips/in. ${ }^{2}$ & & Kips/in.2 & \\
\hline \multirow{2}{*}{0.022} & $\{10,600$ & 0.321 & 10,700 & 0.329 & 10,500 & 0.310 \\
\hline & 10,600 & .323 & 10,500 & .331 & 10,700 & .323 \\
\hline \multirow{2}{*}{.032} & $\{10,400$ & .329 & 10,400 & .318 & 10,300 & .322 \\
\hline & 10,300 & .319 & 10,500 & .326 & 10,400 & .330 \\
\hline \multirow{2}{*}{.064} & 10,500 & .323 & 10,400 & .331 & 10,400 & .327 \\
\hline & 10,700 & .328 & 10,500 & .328 & 10,500 & .320 \\
\hline & 10,000 & .315 & 10,000 & .320 & 9,900 & .314 \\
\hline \multirow[t]{2}{*}{.081} & 10,100 & .312 & 9,900 & .312 & 10,000 & .316 \\
\hline & 10,000 & .311 & t & $\ldots$ & 9,900 & .314 \\
\hline
\end{tabular}

ALUMINUM ALLOY 24SRT

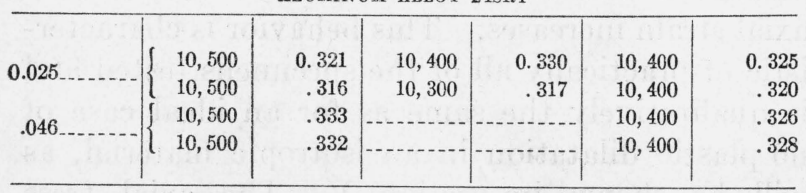

CHROME-MOLYBDENUM STEEL

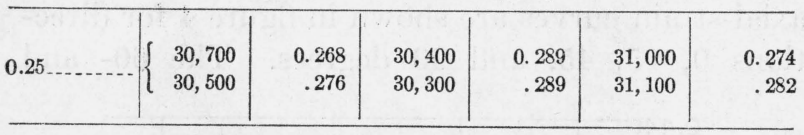

CARBON STEEL, FULLY KILLED, AT $-44^{\circ}$ C

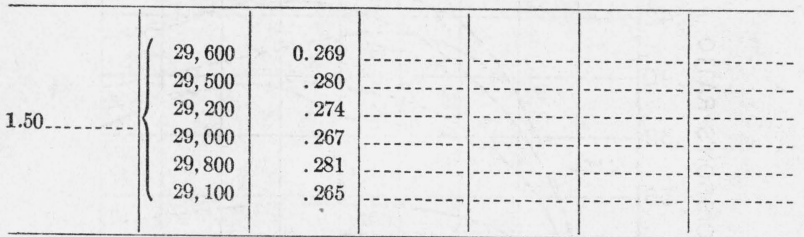

CARBON STEEL, FULLY KILLED, AT ROOM TEMPERATURE

\begin{tabular}{r|r|r|r|r|r|r}
\hline 28,850 & 0.270 & 28,570 & 0.263 & 28,220 & 0.270 \\
28,820 & .267 & 28,450 & .267 & 28,430 & .268 \\
28,480 & .273 & 28,500 & .263 & 28,500 & .274 \\
28,350 & .267 & 28,620 & .270 & 28,500 & .275 \\
28,500 & .269 & 28,410 & .274 & 28,430 & .279 \\
28,480 & .277 & 28,400 & .274 & 28,480 & .271 \\
\hline
\end{tabular}

STRUCTURAL STEEL PLATES AND ANGLES

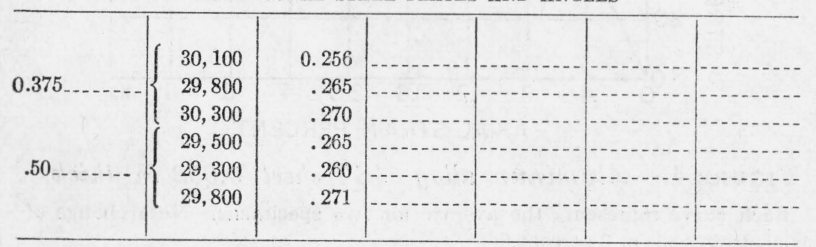

of the curves for directions within about 30 degrees from the direction of rolling.

\section{Aluminum Alloy 24ST}

The values of Young's modulus of elasticity and Poisson's ratio in the elastic range for the individual specimens are given in table 2 .
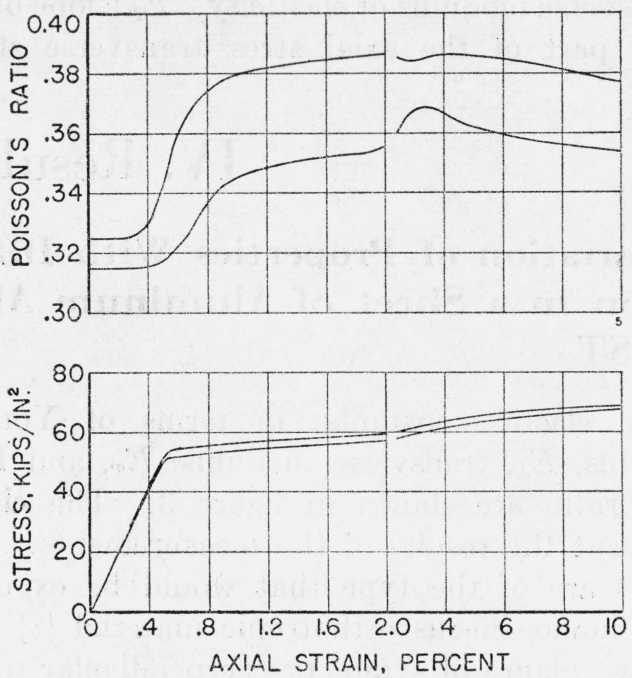

FjGURE 5.-Aluminum alloy $24 S T$ sheet, direction 0 degrees.

The upper curve is the average plus the standard deviation, and the lower curve is the average minus the standard deviation for 9 to 12 specimens $0.022,0.032,0.064$, or 0.081 in. thick. Note change of axial-strain scale at 2 percent.
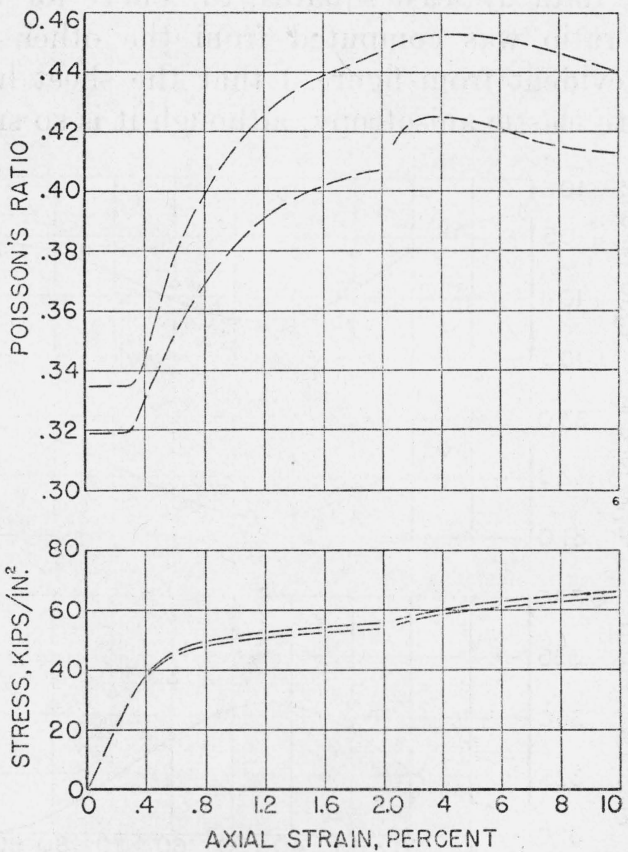

Figurf 6.-Aluminum alloy $24 S T$ sheet, direction 45 degrees. The upper curve is the average plus the standard deviation, and the lower curve is the average minus the standard deviation for 8 to 10 specimens $0.022,0.032,0.064$, or $0.081 \mathrm{in}$. thick. Note change in axial-strain scale at 2 percent. 
The 0.092- and 0.125-in.-thick specimens were not tested in the elastic range.

The averages, plus or minus standard deviations, of the stress and Poisson's ratio are shown in figures 5, 6, and 7 for directions 0 , 45, and 90 degrees, respectively. The scatter in the valu'es of stress and Poisson's ratio for a given axial strain was no greater in the group consisting of specimens $0.022,0.032,0.064$, and $0.081 \mathrm{in}$. thick than it was for specimens of the same thickness; the results for these four thicknesses were therefore averaged.
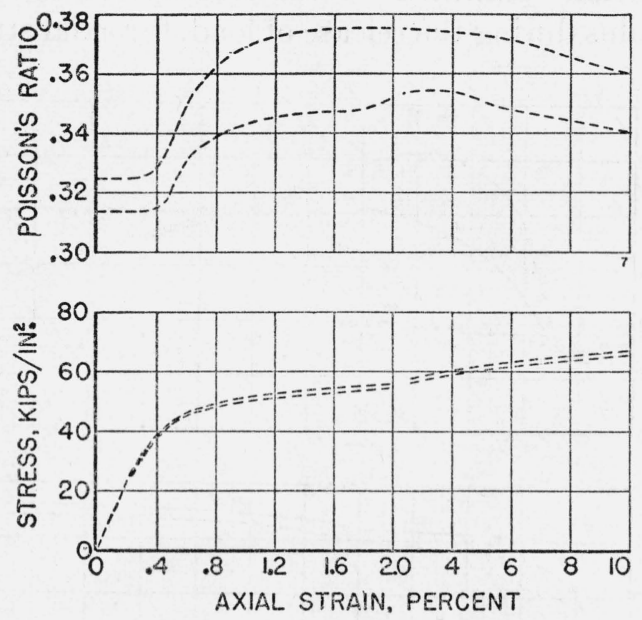

FIGURE 7.-Aluminum alloy $24 S T$ sheet, direction 90 degrees.

The upper curve is the average plus the standard deviation, and the lower curve is the average minus the standard deviation for 9 to 12 specimens $0.022,0.032,0.064$, or 0.081 in thick. Note change of axial-strain scale at 2 percent.
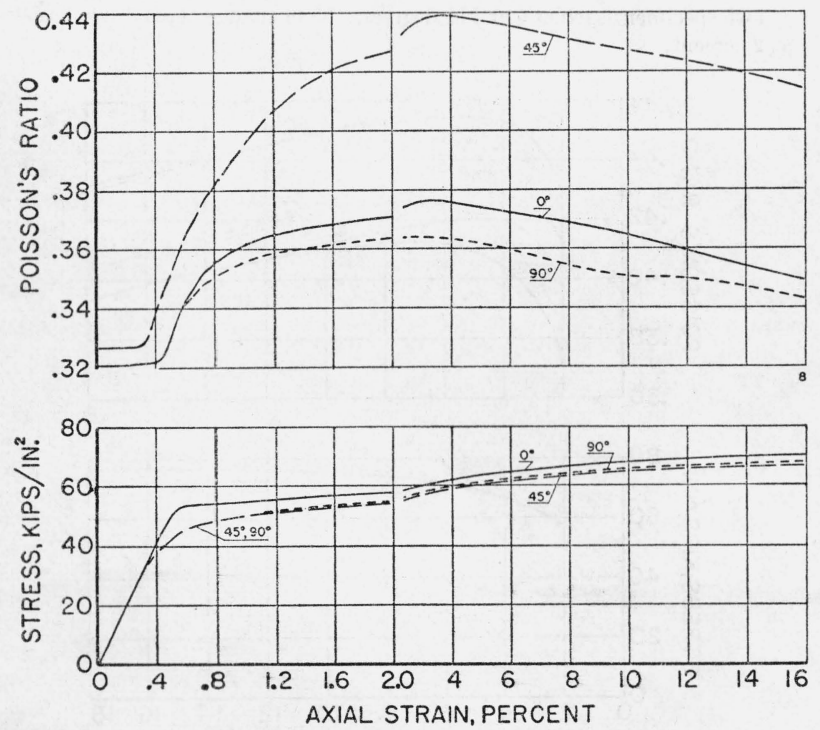

Frgure 8.-Aluminum alloy $24 S T$ sheet.

Average values for the specimens of figures 5, 6, and 7 . Note change of axial-strain scale at 2 percent.
Somewhat less than two-thirds of the data lies in the dispersion band bounded by the two curves in each case. The results are summarized in figure 8, which shows the average values of the stress and of Poisson's ratio for each of the three directions.

The results for the individual specimens 0.092 and 0.125 in. thick are shown in figures 9 and 10 , respectively.
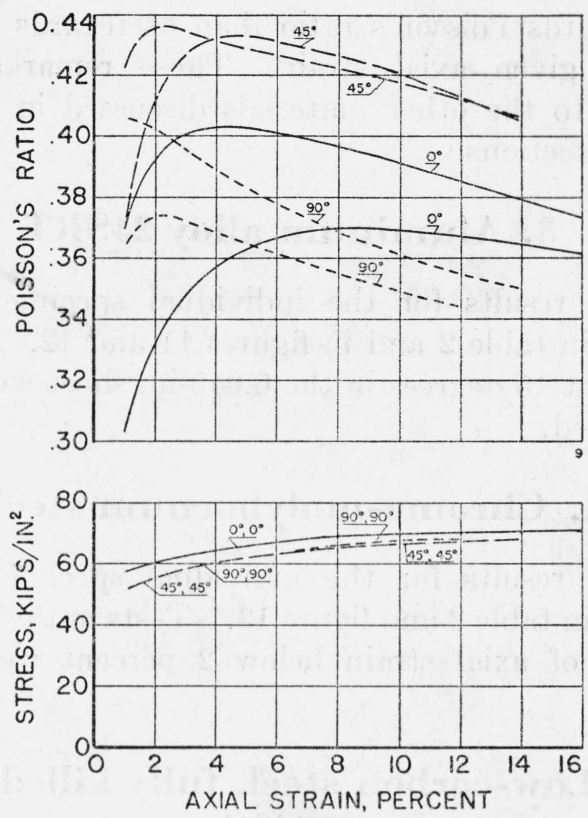

Frgure 9.-Aluminum alloy $24 S T$ sheet, 0.092 in. thick. Two specimens each at 0,45 , and 90 degrees.
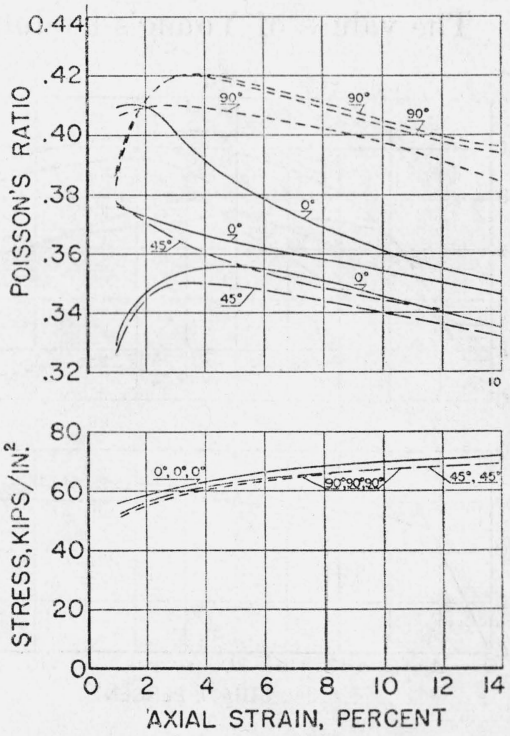

Figure 10.-Aluminum alloy $24 S T$ sheet, 0.125 in. thick. Three specimens each at 0 and 90 degrees, 2 at 45 degrees. 
In many cases there are large discrepancies in the values of Poisson's ratio for two nominally identical specimens, especially for the smaller plastic strains. The accumulation of error that occurs when one strain is divided by another in the process of computing Poisson's ratio accounts for a considerable part of this discrepancy. It is felt, however, that the results indicate an inherent variability in the material itself which is greater as regards Poisson's ratio than as regards stress, for a given axial strain. These remarks also apply to the other materials discussed in subsequent sections.

\section{Aluminum alloy 24 SRT}

The results for the individual specimens are given in table 2 and in figures 11 and 12 . Specimens at 45 degrees in the 0.045 -in. sheet were not obtained.

\section{Chrome-molybdenum steel}

The results for the individual specimens are given in table 2 and figure 13. Tests in the plastic range of axial strain below 2 percent were not made.

\section{Low-carbon steel, fully killed, at $-44^{\circ} \mathrm{C}$}

All six of these specimens were parallel to the directions of rolling. They were tested at about $-44^{\circ} \mathrm{C}$. The values of Young's modulus and of
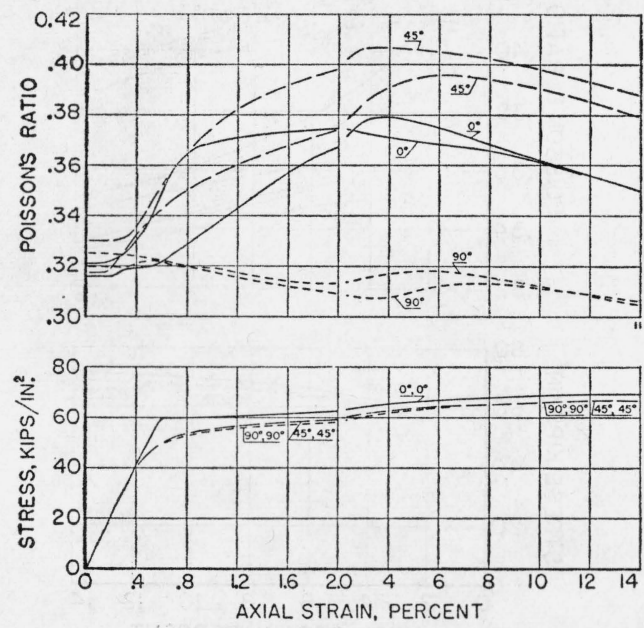

Figdre 11.-Aluminum alloy $24 S R T$ sheet, 0.025 in. thick. Two spesimens each at 0,45 , and 90 degrees. Note change of axial-strain ale at 2 percent.
Poisson's ratio in the elastic range are given in table 2. The results in the plastic range are shown in figure 14 as averages, plus or minus standard deviations.

These specimens were assumed to be transversely isotropic so that the dilatation could be computed as a function of axial strain. This was done by using the average values of Poisson's ratio for the six specimens. The results are shown by the upper curve (full line) of figure 15. The lower curve (full line) shows the elastic (recoverable) dilatation computed on the assumption that the modulus during the release of load, for axial strains
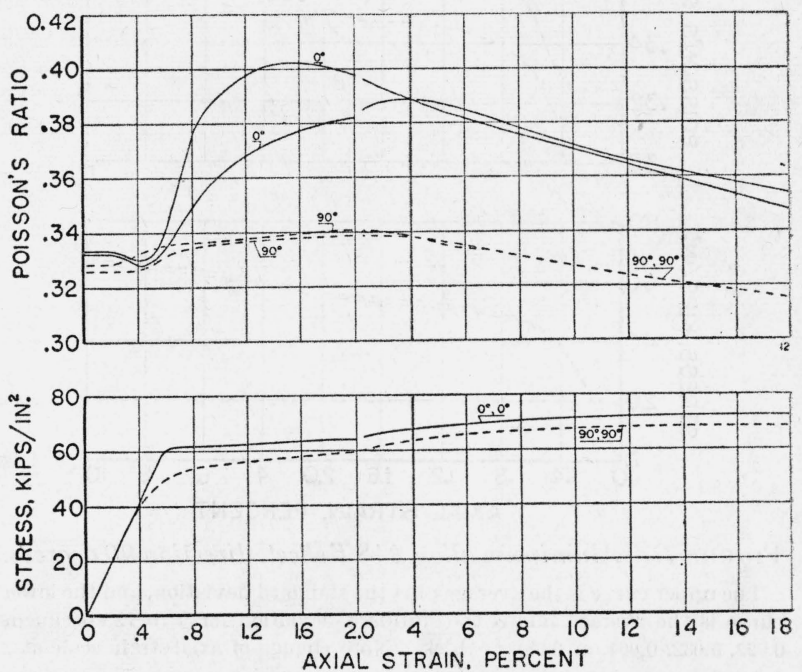

FugURe 12.-Aluminum alloy $24 S R T$ sheet, 0.046 in. thick. Two specimens each at 0 and 90 degrees. Note change of axial-strain scale at 2 percent.
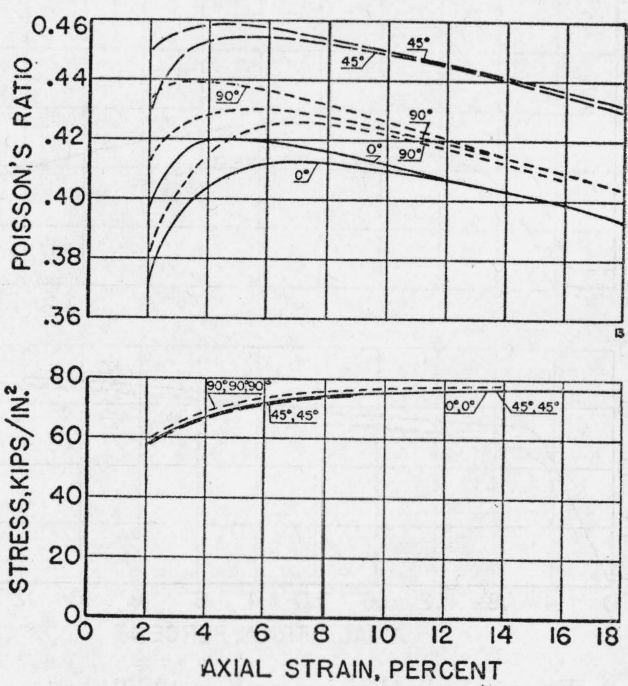

Figure 13.-Chrome-molybdenum steel plate, 1/4 in. ihick. Two specimens each at 0 and 45 degrees, three at 90 degrees. 
less than 1 percent was equal to the value of Young's modulus for the material. It is seen that after yielding has begun the permanent dilatation is a large part of the total.

\section{Low-carbon steel, fully killed, at room temperature}

The results for the individual specimens are given in table 2 . The averages, plus or minus standard deviations, of the stress and Poisson's ratio are shown in figures 16,17 , and 18 for directions 0,45 , and 90 degrees, respectively.

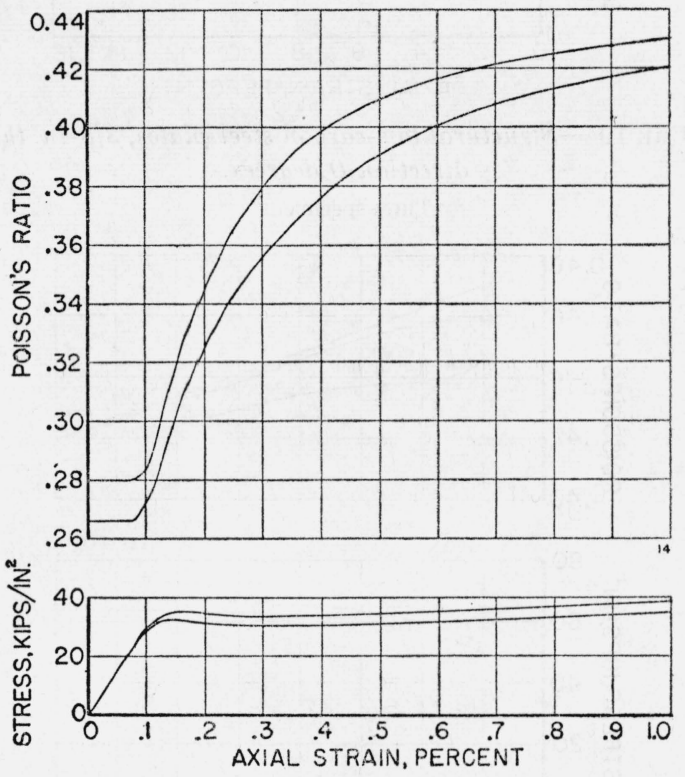

Figure 14.-Fully killed low-carbon steel plate, $1 \frac{11}{2}$ in. thick, at $-44^{\circ} \mathrm{C}$.

The upper curve is the average plus the standard deviation, and the lower curve is the average minus the standard deviation for 6 specimens at 0 degrees.

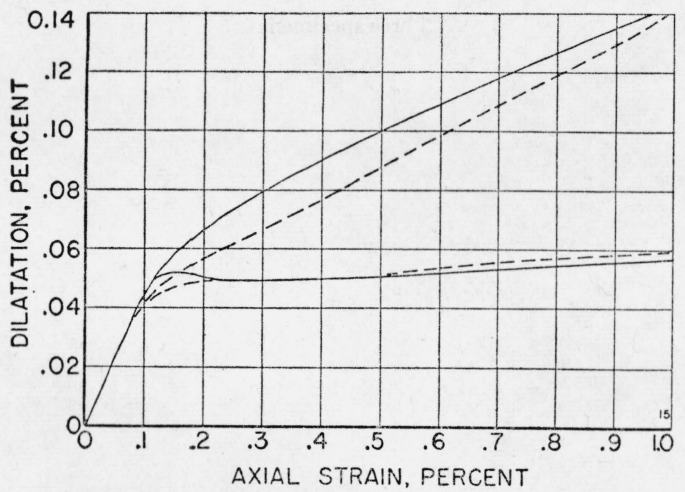

F1GURe 15.-Fully killed low-carbon steel at $-44^{\circ} C$ (full line) and at room temperature (broken line).

Dilatation as a function of axial strain. The upper curve shows the total, and the lower curve the elastic dilatation.
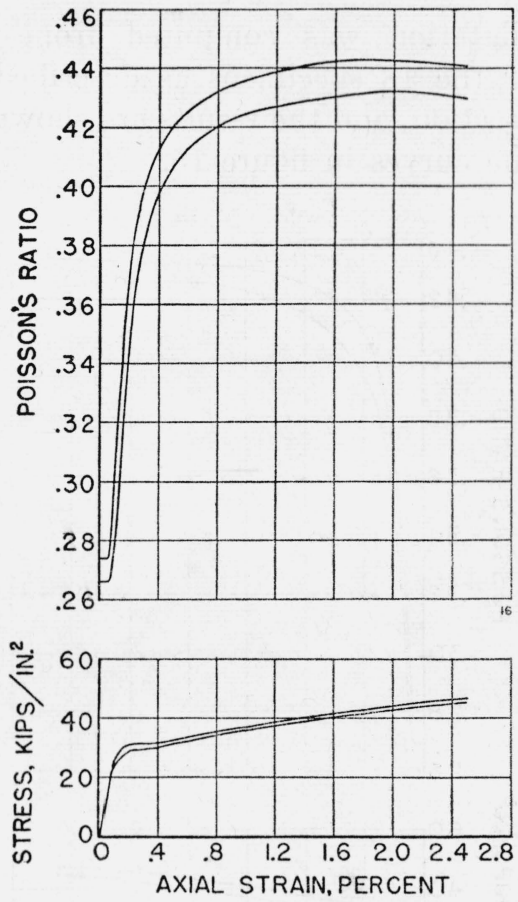

Frgure 16.-Fully killed low-carbon steel plates, 1.5 in. thick, direction 0 degrees

The upper curve is the average plus the standard deviation, and the lower curve is the average minus the standard deviation for 6 specimens.
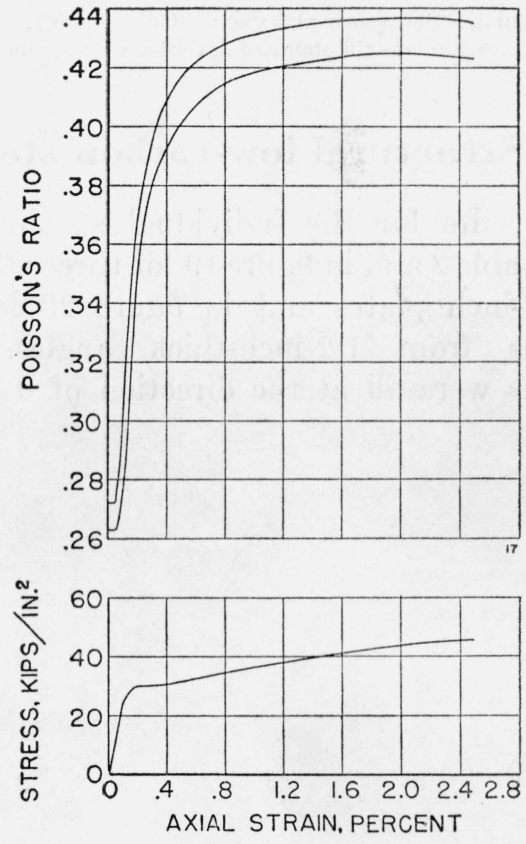

Figure 17.-Fully killed low-carbon steel plates, $1.5 \mathrm{in}$. thick, direction 45 degrees

The upper curve is the average plus the standard deviation, and the lower curve is the average minus the standard deviation for 6 specimens. 
The dilatation was computed from average values for the 18 specimens as described in the previous section, and the results are shown by the broken-line curves in figure 15 .
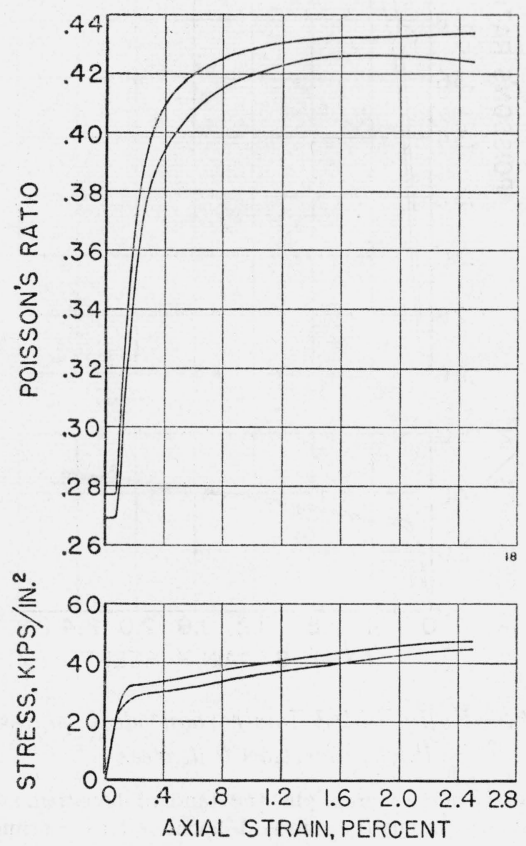

Frgure 18.-Fully killed low-carbon steel plates, $1.5 \mathrm{in.}$ thick, direction 90 degrees

The upper curve is the average plus the standard deviation, and the lower curve is the average minus the standard deviation for 6 specimens.

\section{Structural low-carbon steel}

The resulis for the individual specimens are given in table 2 and in figure 19 for three specimens from 3/8-inch plates and in figure 20 for three specimens from $1 / 2$-inch-thick angles. These specimens were all at the direction of 0 degrees.
Tests in the plastic range of axial strain below 2 percent were not made.
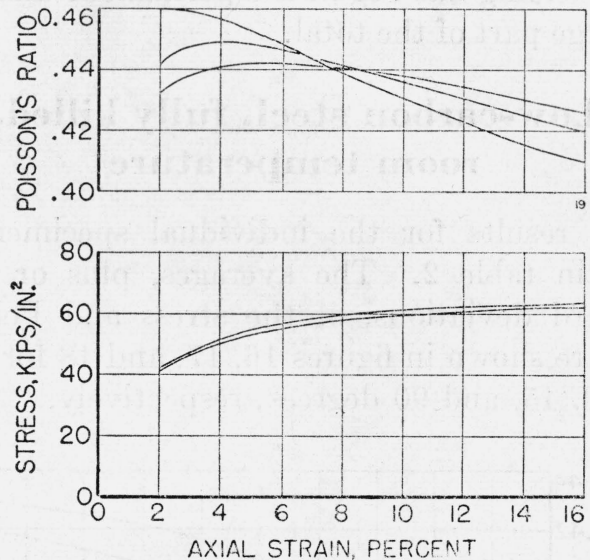

FIGURE 19 -Structural low-carbon steel plates, 3/8-in. thick, direction 0 degrees.

Three specimens
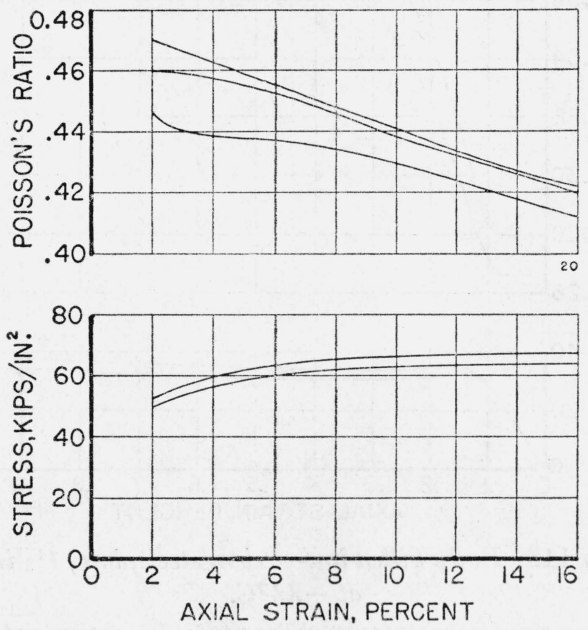

FigURE 20.-Structural low-carbon steel angles, 1/2-in. thick, direction 0 degrees.

Three specimens 


\section{Appendix-Variation of Poisson's Ratio With Axial Strain in an Ideal Case}

It is instructive to consider the variation of Poisson's ratio, $\nu$, in a simple case, say a material having a stressstrain curve as shown in figure 21, which is a horizontal line in the plastic range and has a sharp knee. If the proportional limit corresponds to an axial strain of 0.005 and Poisson's ratio in the elastic range is 0.3 , the elastic dilatation is 0.002 for axial strain, $\epsilon_{a}$, greater than 0.005 . The dilatation, $\delta$, is

$$
\delta=\left(1+\epsilon_{a}\right)\left(1-\nu \epsilon_{a}\right)^{2}-1,
$$

from which

$$
\nu=\frac{1-\left(\frac{1+\delta}{1+\epsilon_{a}}\right)^{1 / 2} .}{\epsilon_{a}}
$$

If there is no plastic dilatation, $\delta=0.002$ for $\epsilon_{a}>0.005$, and the variation of $\nu$ with $\epsilon_{a}$ is as shown in figure 21 . It is seen that $\nu$ rises from the elastic value of 0.3 to a maximum of 0.463 at about $\epsilon_{a}=0.05$, and then decreases steadily.
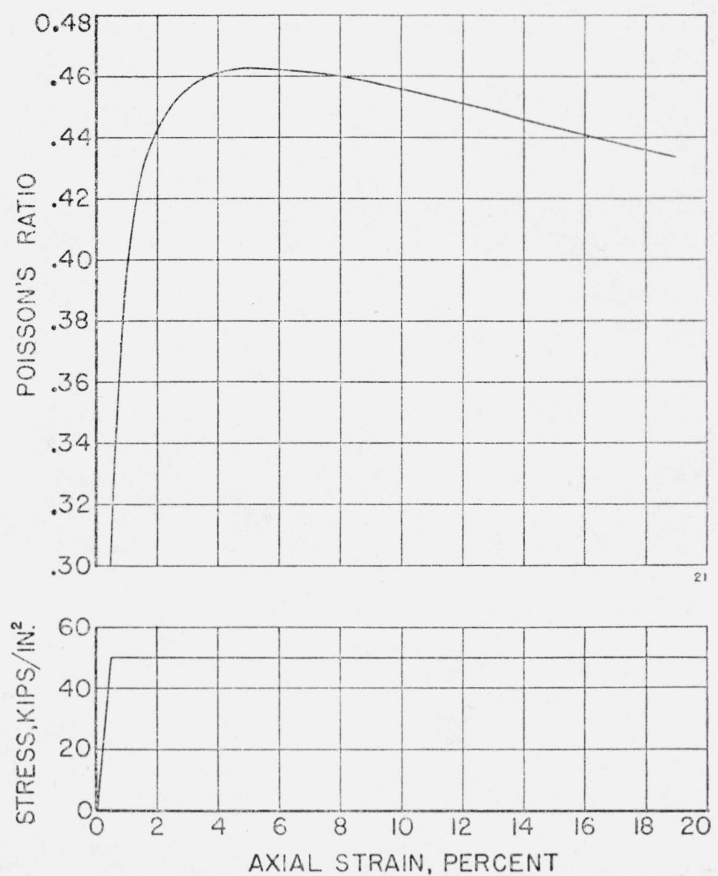

Figure 21.-Variation of Poisson's ratio with axial strain in an ideal case.

Elastic dilatation 0.2 percent for strains greater than 0.5 percent, no plastic dilatation

\section{References}

[1] J. M. Lessells and C. W. MacGregor, Certain phases of the combined stress problem, Proc. Fifth Int. Cong. Applied Mech. 201 (1938).

[2] Rudolph Plank, Das Verhalten des Querkontraktionskoeffizienten des Eisens bis zu sehr grossen Dehnungen, Z. Verein Deut. Ing. 55-2, 1479 (1911).

[3] Report of committee on manual on presentation of data, Proc. ASTM 33-1, 465 (1933).

[4] G. I. Taylor, and H. Quinney, The plastic distortion of metals, Phil. Trans. Roy. Soc. (London) [A] 230 , 323 (1931).
[5] A. Nadai, Plasticity, p. 86. (McGraw-Hill Book Co., Inc., New York, N. Y., 1931).

[6] Martin Greenspan and Leroy R. Sweetman, A transfer strain gage for large strains, J. Research NBS $\mathbb{i}$, 595 (1945) RP1658.

[7] H. M. Goodwin, Precision of measurements and graphical methods, p. 60 (McGraw-Hill Book Co., Inc., New York, N. Y., 1913)

[8] A. E. H. Love, A treatise on the mathematical theory of elasticity, p. 161, 4th ed. (Cambridge Press, 1927)

Washington, July 10, 1946. 